\title{
Microwave and Infrared Drying Characteristics of Mango Slices
}

\author{
İbrahim Doymaz \\ Department of Chemical Engineering, Yildiz Technical University, Esenler, Istanbul, Turkey \\ Tel: +90 21238347 48, Fax: +90 212383 4725, E-mail: doymaz@yildiz.edu.tr \\ Received: 15 January 2017 \\ Accepted: 1 June 2017 \\ DOI: $10.18466 /$ cbayarfbe.339337
}

\begin{abstract}
In this study, mango slices were dried with using both microwave and infrared methods. The microwave and infrared power levels are determined between $90-800 \mathrm{~W}$ and $75-104 \mathrm{~W}$, respectively. The results of this study show that microwave and infrared power levels have an effect on drying kinetics. Five thin-layer drying models that were widely used in the literature were applied to the experimental data and the effective moisture diffusivity, activation energy and energy consumptions are also calculated. Midilli \& Kucuk model was the best fits of experimental data for both microwave and infrared drying. The effective moisture diffusivity values were determined to be between $2.28 \times 10^{-9}$ and $4.66 \times 10^{-8} \mathrm{~m}^{2} / \mathrm{s}$, and $5.07 \times 10^{-10}-1.27 \times$ $10^{-9} \mathrm{~m}^{2} / \mathrm{s}$ for microwave and infrared drying, respectively. The values of activation energy for microwave and infrared drying were found as 39.135 and $4.482 \mathrm{~kW} / \mathrm{kg}$, respectively.
\end{abstract}

Keywords - Drying, Effective Moisture Diffusivity, Infrared, Mango, Microwave.

\section{Introduction}

Mango is a type of a cultivated fruit, which belong to the genus Mangifera, consisting of numerous tropical fruiting trees. The main family of the mango is Anacardiaceae and the native of this fruit is belongs to South Asia [1]. World production of mangoes in 2013 was 42.66 million tons. Five largest producers in the World were India, China, Thailand, Indonesia and Mexico with the productions of $18.00,4.45,3.14,2.06$ and 1.90 million tons, respectively [2]. The energy value per $100 \mathrm{~g}$ mango is $250 \mathrm{~kJ}$ (60 $\mathrm{kCal}$ ), and contains significant amounts of the daily values of vitamin $\mathrm{C}$ and folate. Also mango contains vitamin $\mathrm{A}$, thiamine (B1), riboflavin (B2), niacin (B3), pantothenic acid (B5), vitamin B6, folate (B9), vitamin E, vitamin K, calcium, iron, magnesium, manganese, phosphorus, and potassium [3]. In spite of its excellence, the perishable nature of this fruit and its short harvest season severely limit its utilization. Drying may be an interesting method in order to prevent fresh fruit deterioration [4].

Moisture content in the food products lead to decay and spoil due to its microbiological activity. For long term preservation, several drying processes are used in the literature. With some disadvantages such as lower energy efficiency and long drying times the simplest method is the hot-air drying method [5-7]. A new efficient method, which is microwave drying method, has been in interest among the researchers for the last two decades. This new method is used due to rapid absorption of heat by water inside the food product that causes rapid removal of water molecules, which leads to the decrease in the drying time and energy. In literature with the method of microwave, several vegetables and fruits are studied by the researchers. Carrot [7], garlic [8], green pea [9], mushroom [10], potato [11], apple [12], blueberry [13], cranberry [14], mango [15], eggplant [16] and mussel [17] are some examples that were studied in the literature by using microwave methods.

Infrared drying has gained popularity as other an alternative drying method for a variety of agricultural products. When infrared radiation is used to warm up or dry moist materials, it penetrates the material where the energy of radiation converts into heat. The infrared radiation technology for drying foods could reduce the drying time, maintain a uniform temperature in the product and provide a better quality for the finished products [18]. This drying method is particularly suitable for thin layers of material with large surface exposed to radiation. By using the infrared method; green beans [6], apples [18], strawberry [19], potato [20], sweet potato [21], and red pepper [22] were studied. 
Drying is a complicated process involving simultaneous, coupled mass and heat transfer, particularly under transient conditions [23]. From an engineering point of view, it is important to develop a better understanding of the controlling parameters of this complex process. Mathematical models of the drying processes are used for designing new or improving existing drying systems or even for the control of the drying process. Many mathematical models have proposed to describe the drying process, of them thin-layer drying models have been widely in use. These models can be categorized as theoretical, semi-theoretical, and empirical. The drying characteristics and kinetics of mango slices have been studied by some investigators $[4,15,24]$.

From the studies in the literature it is seen that the microwave and infrared drying kinetics of mango slices were not studied in detail. So in this study, the thin-layer drying behaviour of mango slices is investigated by using five thin-layer drying models then the values of effective moisture diffusivity and activation energies are calculated.

\section{Material And Methods 2.1 Samples}

Mangos are purchased from a local market in Istanbul. Mango slices were cut into layers of $0.5 \mathrm{~cm}$ thickness. Initial moisture content of mango slices was determined using the AOAC-Method 934.06 [25] in an Ecocell LSISB2V/EC55 (MMM Medcenter Einrichtungen GmbH, Planegg, Germany) model oven at $105^{\circ} \mathrm{C}$ for $24 \mathrm{~h}$.

\subsection{Drying Procedure}

Microwave drying experiments were carried out in a Bosch HMT72G420 (Robert Bosch Hausgerate GmbH, Munich, Germany) domestic microwave oven (Maximum output: $800 \mathrm{~W}, 2450 \mathrm{MHz}$. Drying experiments was made using the microwave power levels between 90 and $800 \mathrm{~W}$. The weights of mango slices are used in the range of 7.6 and $9.7 \mathrm{~g}$ in these experiments.

Infrared drying experiments were carried out in a Snijders Moisture Balance, which has a $250 \mathrm{~W}$ halogen lamp (Snijders b.v., Tilburg, Holland). The drying experiments were performed at infrared power level varying from 75 to $104 \mathrm{~W}$. The weight of the used mango slices used in the experiments is $25 \pm 0.5 \mathrm{~g}$.

At the end of the determined time, the samples were removed of each dryer and their weights were recorded using an Ohaus PA214C digital balance, which has an accuracy of $0.001 \mathrm{~g}$ (Ohaus Corporation, NY, USA). When the moisture contents decreased to $0.5-0.6 \mathrm{~kg}$ water/kg dry matter in microwave drying and $0.15 \mathrm{~kg}$ water/kg dry matter in infrared drying process experiments were stopped. Final moisture content of microwave is higher than the infrared moisture content due to the fast burning of samples below $0.5 \mathrm{~kg}$ water $/ \mathrm{kg}$ dry matter.

Dried mango slices were cooled in a desiccator and packed in low density polyethylene bags. Drying experiments were repeated three times and average moisture contents were used in the drying curve plots.

\subsection{Mathematical modelling}

The moisture content is calculated using Equation (2.1)

$$
M=\frac{m_{w}}{m_{d}}
$$

where $M$ is the moisture content ( $\mathrm{kg}$ water/ $\mathrm{kg}$ dry matter), $\mathrm{m}_{\mathrm{w}}$ is the water content $(\mathrm{g})$ and $\mathrm{m}_{\mathrm{d}}$ is the dry matter content $(\mathrm{g})$.

Drying rate is calculated using (2.2):

$$
D R=\frac{M_{t+d t}-M_{t}}{d t}
$$

where $D R$ is the drying rate (kg water/kg dry matter $\times$ $\min ), M_{t+d t}$ is the moisture content at $\mathrm{t}+\mathrm{dt}$ ( $\mathrm{kg}$ water/kg dry matter) and $t$ is the drying time (min).

Moisture ratio was calculated using (2.3):

$$
M R=\frac{M_{t}-M_{e}}{M_{i}-M_{e}}
$$

where $M R$ is the moisture ratio (dimensionless), $\mathrm{M}_{\mathrm{t}}, \mathrm{M}_{\mathrm{e}}$ and $\mathrm{M}_{\mathrm{i}}$ are the moisture content at selected time, at equilibrium and the initial value in $\mathrm{kg}$ water/kg dry matter. The experimental data of MR obtained at different microwave and infrared power levels were fitted to five thin-layer drying models, where the models used are given in Table 1 .

Table 1. Models used for fitting the experimental data

\begin{tabular}{|l|l|c|}
\hline Model Name & Equation & Reference \\
\hline Aghbashlo et al. & $M R=\exp \left(-\frac{k_{1} \times t}{1+k_{2} \times t}\right)$ & {$[26]$} \\
\hline $\begin{array}{l}\text { Henderson \& } \\
\text { Pabis }\end{array}$ & $M R=a \times \exp (-k \times t)$ & {$[27]$} \\
\hline Logaritmic & $M R=a \times \exp (-k \times t)+c$ & {$[17]$} \\
\hline Midilli \& Kucuk & $M R=a \times \exp \left(-k \times t^{n}\right)+b \times t$ & {$[28]$} \\
\hline Parabolic & $M R=a+b \times t+c \times t^{2}$ & {$[29]$} \\
\hline
\end{tabular}

\subsection{Statistical Analysis}

Based on the Lavenberg-Marquardt algorithm, model parameters were estimated using a non-linear regression 
procedure by the help of Statistica 8.0 computer programme (StatSoft Inc., Tulsa, USA). The predicted data obtained were evaluated by the coefficient of determination $\left(\mathrm{R}^{2}\right)$, reduced chi-square $\left(\chi^{2}\right)$, and root mean square error (RMSE). Since, higher $\mathrm{R}^{2}$ values and lower $\chi^{2}$ and RMSE values were accepted as better results $[15,17]$. The equations of $\mathrm{R}^{2}, \chi^{2}$ and RMSE are given in (2.4), (2.5) and (2.6), respectively:

$$
\begin{gathered}
R^{2}=1-\frac{\sum_{i=1}^{N}\left(M R_{\text {exp }, i}-M R_{\text {pre }, i}\right)^{2}}{\sum_{i=1}^{N}\left(M R_{\text {exp }, i}-\left(\frac{1}{n}\right) \sum_{i=1}^{N} M R_{\text {exp }, i}\right)} \\
\chi^{2}=\frac{\sum_{i=1}^{N}\left(M R_{\text {exp }, i}-M R_{\text {pre }, i}\right)^{2}}{N-z} \\
\text { RMSE }=\left(\frac{1}{N} \sum_{i=1}^{N}\left(M R_{\text {pre }, i}-M R_{\text {exp }, i}\right)^{2}\right)^{1 / 2}
\end{gathered}
$$

where $M R_{\text {exp }}$ and $M R_{\text {pre }}$ represent experimental and predicted values of moisture ratio, respectively. $N$ is the total number of data obtained, and $z$ is the number of constants in the model.

\section{Calculation of effective moisture diffusivity}

In the drying of agricultural products, Fick's second law of diffusion equation, which symbolized as a massdiffusion equation in the falling rate period, is shown in (2.7):

$$
\frac{\partial M}{\partial t}=\square\left[D_{e f f}(\square M)\right]
$$

The analytical solution of Fick's second law (2.7) unsteady state diffusion with the assumptions of moisture migration due to diffusion, negligible shrinkage, constant diffusion coefficients and temperature during the drying process is given in (2.8):

$$
M R=\frac{8}{\pi^{2}} \sum_{n=0}^{\infty} \frac{1}{(2 n+1)^{2}} \exp \left(-\frac{(2 n+1)^{2} \pi^{2} D_{e f f} t}{4 L^{2}}\right)
$$

where $D_{\text {eff }}$ is the effective moisture diffusivity $\left(\mathrm{m}^{2} / \mathrm{s}\right)$, $\mathrm{t}$ is the drying time (s), $\mathrm{L}$ is the half-thickness of samples (m) and $n$ is the positive integer. In Equation (2.8) the first term is significant and the equation can be simplified and written into logarithmic form as:

$$
\ln (M R)=\ln \left(\frac{8}{\pi^{2}}\right)-\left(\frac{\pi^{2} D_{e f f} t}{4 L^{2}}\right)
$$

So the values of $D_{\text {eff }}$ can be determined by the slope of the curve obtained by plotting experimental drying data in terms of $\ln (\mathrm{MR})$ versus drying time.

$$
D_{e f f}=-\frac{\text { slope } \times 4 L^{2}}{\pi^{2}}
$$

\section{Determination of activation energy}

Temperature is not directly measurable quantity in the microwave and infrared drying processes. Given by Kipcak [17], the activation energy can be calculated by the modified form of Arrhenius equation, where the equation shows the relationship between the effective moisture diffusivity and the microwave power to sample weight instead of temperature:

$$
D_{\text {eff }}=D_{0} \exp \left(-\frac{E_{a} \times m}{P}\right)
$$

$D_{0}$ is the pre-exponential factor of Arrhenius equation $\left(\mathrm{m}^{2} / \mathrm{s}\right), E_{a}$ is the activation energy (W/kg), $P$ is the microwave power (W) and $\mathrm{m}$ is the sample weight $(\mathrm{kg})$.

\section{Results and Discussion}

\subsection{Drying curves}

Drying curve of moisture content with respect to time for mango slices is given in Figures 1 and 2.

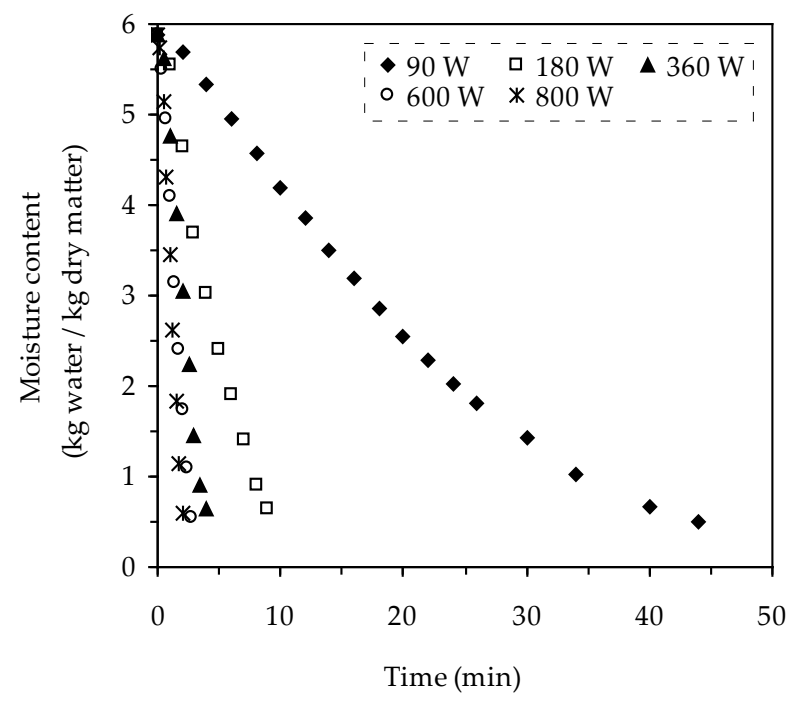

Figure 1. Microwave drying curves of moisture content with respect to time for mango slices 
Celal Bayar University Journal of Science

Volume 13, Issue 3, p 681-688

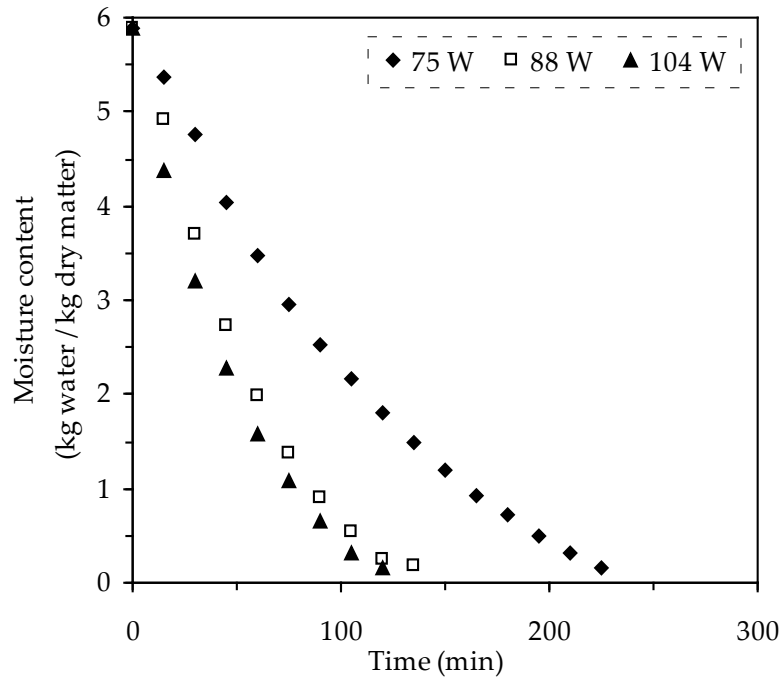

Figure 2. Infrared drying curves of moisture content with respect to time for mango slices

As the microwave and infrared power level increased the moisture contents were decreased faster. The drying time required reaching the final moisture content of samples were found as 44, 10, 4.5, 2.67 and 2 min for the microwave power levels of 90,180, 360, 600, and $800 \mathrm{~W}$, respectively. On the other hand, for infrared dying the drying times were increased to 225, 135 and 120 min for the infrared power levels of 75, 88 and $104 \mathrm{~W}$, respectively. As expected at higher microwave and infrared power levels, higher heat absorption caused higher product temperature, higher mass transfer driving force, faster drying rate and lesser drying time. This observation is in mutual agreement with the results reported in the literature for microwave and infrared drying of different products such as green bean [6], mussel [17], red pepper [22], onion [30], and spinach leaves [31].

\section{Drying rate}

Drying rate curves obtained from the experimental data for microwave and infrared drying processes are given in Figures 3 and 4 . All three rate periods namely increasingrate, constant-rate and falling-rate were obtained in the microwave drying process. On the other hand, increasingrate and falling-rate periods were seen in the process of infrared drying. Here, the increasing-rate periods is explained as adaptation period and generally it can be negligible. It is observed that the drying rates are increased with increasing microwave and infrared power levels. The decrease in drying time with an increase in the microwave and infrared power level has been reported for other food materials, including and green bean [6], onion [32], and pomegranate aril [33]

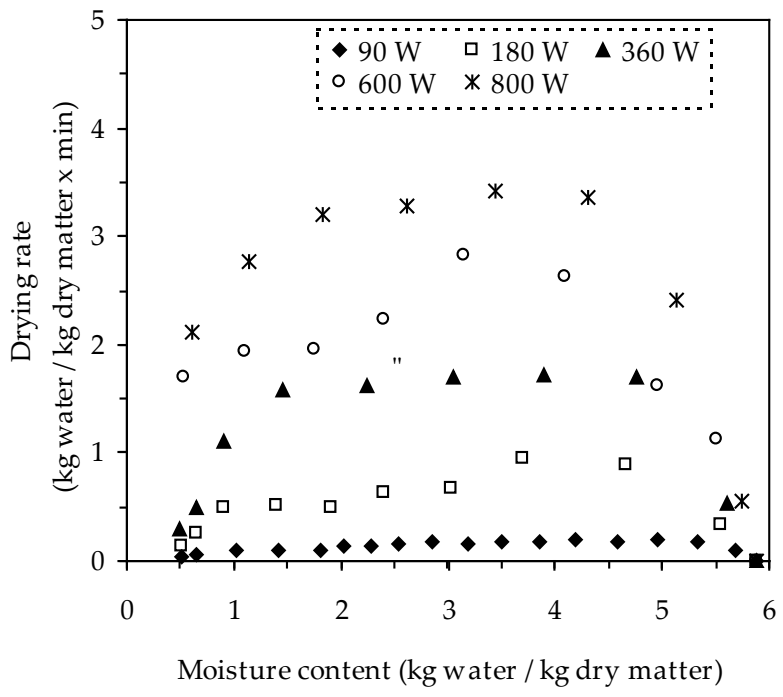

Figure 3. Microwave drying rate curves of mango slices

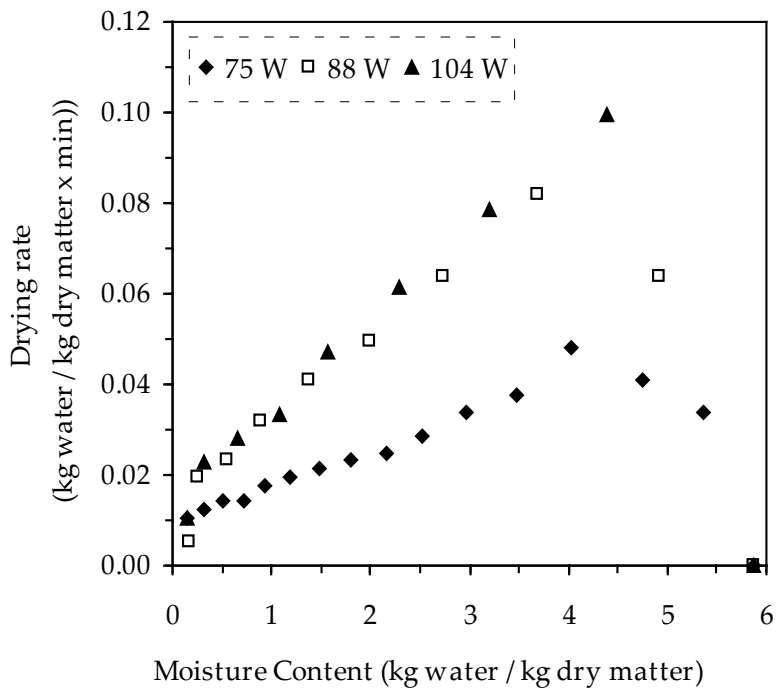

Figure 4. Infrared drying rate curves of mango slices

\section{Evaluation of the drying models}

Estimated model coefficients and statistical data obtained from different drying models are shown in Tables 2 and 3. According to the data obtained, the best model is selected as Midilli \& Kucuk based on the highest $\mathrm{R}^{2}$ and the lowest $\chi^{2}$, and RMSE values. In microwave drying process, the highest $\mathrm{R}^{2}$, lowest $\chi^{2}$, and RMSE values are found between 0.998004- 0.999883, 0.000011-0.000205, and $0.003084-0.012199$, respectively. On the other hand, in infrared drying process, the highest $\mathrm{R}^{2}$, lowest $\chi^{2}$, and RMSE values are found between 0.999618-0.999888, $0.000494-0.001305$, and $0.019606-0.034984$, respectively. To compare the selected model, the plots of experimental MR and predicted MR by Midilli \& Kucuk are 
given in Figures 5 and 6 . These curves were very close to mental and predicted moisture ratio. the bisector showing a good agreement between experi-

Table 2. Estimated coefficients and statistical data obtained from different drying models microwave drying of mango slices

\begin{tabular}{|c|c|c|c|c|c|c|}
\hline \multirow{2}{*}{$\begin{array}{l}\text { Model } \\
\text { No }\end{array}$} & \multirow{2}{*}{ Coefficients } & \multicolumn{5}{|c|}{ Power (W) } \\
\hline & & 90 & 180 & 360 & 600 & 800 \\
\hline \multirow{5}{*}{ Aghbashlo et al. } & $\mathrm{k}_{1}$ & 0.030973 & 0.122574 & 0.219221 & 0.279011 & 0.315482 \\
\hline & $\mathrm{k}_{2}$ & -0.011547 & -0.056808 & -0.159697 & -0.266334 & -0.379875 \\
\hline & $\mathrm{R}^{2}$ & 0.998626 & 0.996722 & 0.994540 & 0.997178 & 0.995189 \\
\hline & $\chi^{2}$ & 0.000251 & 0.000794 & 0.001499 & 0.000712 & 0.001250 \\
\hline & RMSE & 0.014946 & 0.025485 & 0.034628 & 0.023537 & 0.031185 \\
\hline \multirow{5}{*}{ Henderson \& Pabis } & $\mathrm{a}$ & 1.079075 & 1.094781 & 1.119263 & 1.109552 & 1.131214 \\
\hline & $\mathrm{k}$ & 0.046393 & 0.205167 & 0.441612 & 0.608009 & 0.774025 \\
\hline & $\mathrm{R}^{2}$ & 0.992227 & 0.986376 & 0.973645 & 0.966794 & 0.957782 \\
\hline & $\chi^{2}$ & 0.001418 & 0.003283 & 0.007159 & 0.008254 & 0.010767 \\
\hline & RMSE & 0.035497 & 0.051824 & 0.075679 & 0.080124 & 0.091511 \\
\hline \multirow{6}{*}{ Logarithmic } & $\mathrm{a}$ & 1.369321 & 1.513256 & 2.049904 & 11.85390 & 16.45200 \\
\hline & $\mathrm{k}$ & 0.028673 & 0.107152 & 0.155684 & 0.031900 & 0.030600 \\
\hline & $\mathrm{c}$ & -0.328163 & -0.464412 & -0.988260 & -10.80910 & -15.37760 \\
\hline & $\mathrm{R}^{2}$ & 0.998409 & 0.996244 & 0.992279 & 0.996405 & 0.993882 \\
\hline & $\chi^{2}$ & 0.000310 & 0.001023 & 0.002419 & 0.001058 & 0.001854 \\
\hline & RMSE & 0.016082 & 0.027278 & 0.041154 & 0.026560 & 0.035156 \\
\hline \multirow{7}{*}{ Midilli \& Kucuk } & $\mathrm{a}$ & 1.002849 & 1.010841 & 0.999765 & 1.000326 & 1.007682 \\
\hline & $\mathrm{k}$ & 0.016256 & 0.090974 & 0.201278 & 0.323615 & 0.490283 \\
\hline & $\mathrm{n}$ & 1.306941 & 1.430547 & 1.794384 & 1.708550 & 1.911859 \\
\hline & $\mathrm{b}$ & -0.000459 & -0.000484 & 0.005756 & -0.030062 & -0.027193 \\
\hline & $\mathrm{R}^{2}$ & 0.999883 & 0.998004 & 0.999166 & 0.999448 & 0.999681 \\
\hline & $\chi^{2}$ & 0.000011 & 0.000205 & 0.000131 & 0.000097 & 0.000048 \\
\hline & RMSE & 0.003084 & 0.012199 & 0.009578 & 0.008025 & 0.005676 \\
\hline \multirow{6}{*}{ Parabolic } & $\mathrm{a}$ & 1.035524 & 1.048227 & 1.066533 & 1.037163 & 1.048582 \\
\hline & $\mathrm{b}$ & -0.036376 & -0.154731 & -0.319957 & -0.358509 & -0.415534 \\
\hline & c & 0.000331 & 0.005666 & 0.020435 & -0.001691 & -0.037384 \\
\hline & $\mathrm{R}^{2}$ & 0.999214 & 0.997153 & 0.993106 & 0.996536 & 0.995228 \\
\hline & $\chi^{2}$ & 0.000153 & 0.000776 & 0.002161 & 0.001020 & 0.001447 \\
\hline & RMSE & 0.011306 & 0.023755 & 0.038898 & 0.026073 & 0.031058 \\
\hline
\end{tabular}

Table 3. Estimated coefficients and statistical data obtained from different drying models for infrared drying of mango slices.

\begin{tabular}{|c|c|c|c|c|}
\hline Model No & Coefficients & $\mathbf{7 5} \mathbf{~ W}$ & $\mathbf{8 8} \mathbf{~ W}$ & $\mathbf{1 0 4} \mathbf{~ W}$ \\
\hline \multirow{2}{*}{$\begin{array}{c}\text { Aghbashlo } \\
\text { et al. }\end{array}$} & $\mathrm{k}_{1}$ & 0.007385 & 0.013577 & 0.018271 \\
\cline { 2 - 5 } & $\mathrm{k}_{2}$ & -0.002141 & -0.003944 & -0.002924 \\
\cline { 2 - 5 } & $\mathrm{R}^{2}$ & 0.999417 & 0.999396 & 0.999824 \\
\hline
\end{tabular}


Celal Bayar University Journal of Science

Volume 13, Issue 3, p 681-688

İ. Doymaz

\begin{tabular}{|c|c|c|c|c|}
\hline & RMSE & 0.010402 & 0.011293 & 0.005928 \\
\hline \multirow{5}{*}{ Henderson \& Pabis } & $\mathrm{a}$ & 1.067332 & 1.058279 & 1.024586 \\
\hline & $\mathrm{k}$ & 0.010745 & 0.019761 & 0.022749 \\
\hline & $\mathrm{R}^{2}$ & 0.992665 & 0.992267 & 0.996771 \\
\hline & $\chi^{2}$ & 0.001357 & 0.001807 & 0.000725 \\
\hline & RMSE & 0.036841 & 0.040333 & 0.025384 \\
\hline \multirow{6}{*}{ Logarithmic } & a & 1.273322 & 1.209528 & 1.116053 \\
\hline & $\mathrm{k}$ & 0.006848 & 0.013816 & 0.017756 \\
\hline & c & -0.250958 & -0.183032 & -0.113311 \\
\hline & $\mathrm{R}^{2}$ & 0.999531 & 0.998435 & 0.999923 \\
\hline & $\chi^{2}$ & 0.000093 & 0.000413 & 0.000020 \\
\hline & RMSE & 0.009332 & 0.018169 & 0.003922 \\
\hline \multirow{7}{*}{ Midilli \& Kucuk } & $\mathrm{a}$ & 5.918746 & 5.889616 & 5.874951 \\
\hline & $\mathrm{k}$ & 0.004707 & 0.006160 & 0.016321 \\
\hline & $\mathrm{n}$ & 1.130777 & 1.257914 & 1.050788 \\
\hline & $\mathrm{b}$ & -0.002302 & -0.001287 & -0.002994 \\
\hline & $\mathrm{R}^{2}$ & 0.999618 & 0.999698 & 0.999888 \\
\hline & $\chi^{2}$ & 0.01305 & 0.001374 & 0.000494 \\
\hline & RMSE & 0.034984 & 0.033157 & 0.019606 \\
\hline \multirow{6}{*}{ Parabolic } & $\mathrm{a}$ & 1.007549 & 1.012988 & 0.980024 \\
\hline & $\mathrm{b}$ & -0.007623 & -0.014276 & -0.015923 \\
\hline & $\mathrm{C}$ & 0.000015 & 0.000052 & 0.000067 \\
\hline & $\mathrm{R}^{2}$ & 0.999461 & 0.999483 & 0.998979 \\
\hline & $\chi^{2}$ & 0.000107 & 0.000136 & 0.000262 \\
\hline & RMSE & 0.010003 & 0.010441 & 0.014284 \\
\hline
\end{tabular}

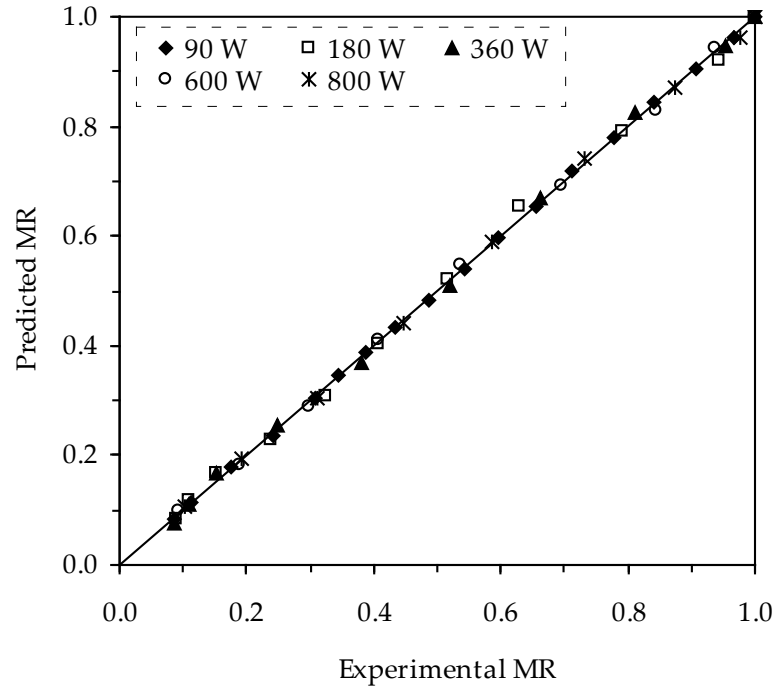

Figure 5. The plot of experimental MR and predicted MR obtained from Midilli \& Kucuk for microwave drying

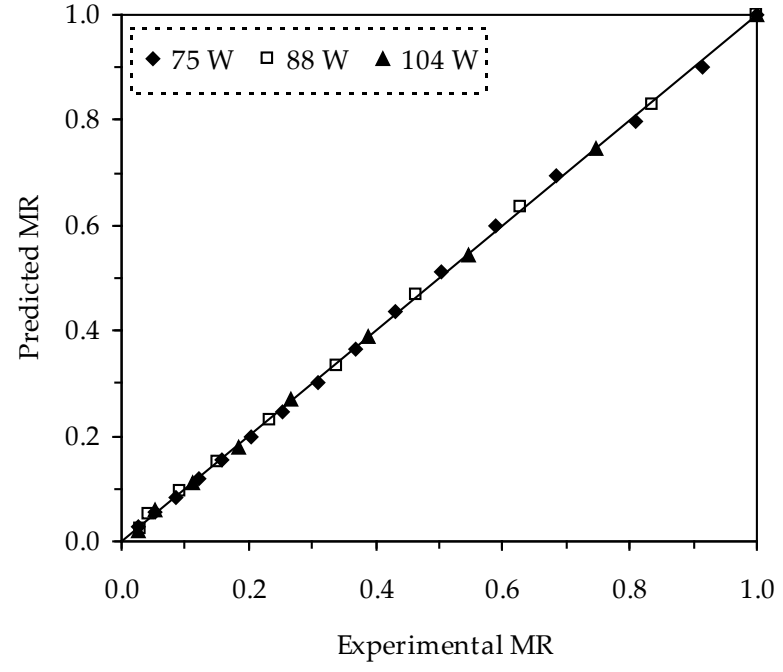

Figure 6. The plot of experimental MR and predicted MR obtained from Midilli \& Kucuk for infrared drying 


\section{Effective moisture diffusivity}

From the plot of $\ln (\mathrm{MR})$ versus drying time for mango slices, the linear equations obtained are given in the Tables 4 and 5 for microwave and for infrared drying, respectively.

Table 4. The equations of $\ln (\mathrm{MR})$ versus drying time and the $D_{\text {eff }}$ values for microwave drying of mango slices

\begin{tabular}{|c|c|c|c|}
\hline $\begin{array}{c}\text { Power } \\
(\mathbf{W})\end{array}$ & Equation & $\mathbf{R}^{2}$ & $\mathbf{D}_{\text {eff }}\left(\mathbf{m}^{2} / \mathbf{s}\right)$ \\
\hline 90 & $\ln (M R)=-0.0009 t+0.1962$ & 0.9809 & $2.28 \times 10^{-9}$ \\
\hline 180 & $\ln (M R)=-0.0043 t+0.2506$ & 0.9522 & $1.09 \times 10^{-8}$ \\
\hline 360 & $\ln (M R)=-0.010 t+0.3224$ & 0.9354 & $2.56 \times 10^{-8}$ \\
\hline 600 & $\ln (M R)=-0.0134 t+0.2944$ & 0.9521 & $3.39 \times 10^{-8}$ \\
\hline 800 & $\ln (M R)=-0.0184 t+0.3354$ & 0.9088 & $4.66 \times 10^{-8}$ \\
\hline
\end{tabular}

Table 5. The equations of $\ln (\mathrm{MR})$ versus drying time and the $D_{\text {eff }}$ values for infrared drying of mango slices

\begin{tabular}{|c|c|c|c|}
\hline $\begin{array}{c}\text { Power } \\
(\mathbf{W})\end{array}$ & Equation & $\mathbf{R}^{2}$ & $\mathbf{D}_{\text {eff }}\left(\mathbf{m}^{2} / \mathbf{s}\right)$ \\
\hline 74 & $\ln (M R)=-0.0002 t+0.3240$ & 0.9379 & $5.07 \times 10^{-10}$ \\
\hline 88 & $\ln (M R)=-0.0004 t+0.3060$ & 0.9709 & $1.01 \times 10^{-9}$ \\
\hline 104 & $\ln (M R)=-0.0005 t+0.2448$ & 0.9691 & $1.27 \times 10^{-9}$ \\
\hline
\end{tabular}

By using the equations in the Tables 4 and 5 , the effective moisture diffusivity values are calculated. As it is seen from the results of $D_{\text {eff }}$ values increased slightly with increasing both microwave and infrared power level, due to the fact that the increase in the power level caused the rapid increase in temperature of the mango slices, which raises the vapour pressure. Calculated $D_{\text {eff }}$ values are within the range of $10^{-12}$ to $10^{-8} \mathrm{~m}^{2} / \mathrm{s}$ for drying of agricultural products [34]. These diffusivities were also close to range from $2.61 \times 10^{-10}$ to $1.09 \times 10^{-9} \mathrm{~m}^{2} / \mathrm{s}$ obtained by Dissa et al. [24] and from $4.97 \times 10^{-10}$ to $1.08 \times 10^{-9} \mathrm{~m}^{2} / \mathrm{s}$ obtained by Akoy [4] during convective drying of mango slices. The effect of microwave and infrared power on the $D_{\text {eff }}$ values can be calculated by the equations of (3.9) and (3.10), respectively.

$$
\begin{aligned}
& D_{\text {eff }}=6 \times 10^{-11} P-3 \times 10^{-10}\left(R^{2}=0.9757\right) \\
& D_{e f f}=3 \times 10^{-11} P-1 \times 10^{-9}\left(R^{2}=0.9389\right)
\end{aligned}
$$

\section{Activation energy calculation}

By using equation (2.11), the plot of $\ln \left(D_{\text {eff }}\right)$ versus $\mathrm{m} / \mathrm{P}$ is drawn for both microwave and infrared drying and the equations of (3.11) and (3.12) are obtained, respectively.

$$
\begin{array}{ll}
\ln \left(D_{\text {eff }}\right)=39135 \times \frac{m}{P}-16.483 & \left(R^{2}=0.9868\right) \\
\ln \left(D_{\text {eff }}\right)=4482 \times \frac{m}{P}-20.14 & \left(R^{2}=0.9905\right)
\end{array}
$$

From the slope and intercept of the lines, $D_{0}$ and $E_{a}$ values are calculated as $6.94 \times 10^{-8} \mathrm{~m}^{2} / \mathrm{s}$ and $39.13 \mathrm{~kW} / \mathrm{kg}$ for microwave drying and $1.79 \times 10^{-9} \mathrm{~m}^{2} / \mathrm{s}$ and $4.48 \mathrm{~kW} / \mathrm{kg}$ for infrared drying.

\section{Conclusions}

In this study, the drying characteristics of mango slices were investigated by using microwave and infrared energy. All three rate periods of increase-rate, constant-rate and falling-rate were seen on the microwave drying, where in the infrared drying the drying process took place in the increase and falling-rate periods. The drying time decreased with the increase in both microwave and infrared power level. From the mathematical modelling results Midilli \&Kucuk model gave the best results for both microwave and infrared drying. The effective moisture diffusivity values were found range from $2.28 \times 10^{-9}$ to $4.66 \times 10^{-8} \mathrm{~m}^{2} / \mathrm{s}$ and $5.07 \times 10^{-10}$ to $1.27 \times 10^{-9} \mathrm{~m}^{2} / \mathrm{s}$, for microwave and infrared drying, respectively. The activation energy values were calculated as $39.13 \mathrm{~kW} / \mathrm{kg}$ and $4.48 \mathrm{~kW} / \mathrm{kg}$ for microwave drying and infrared drying, respectively. In conclusion the method of microwave drying is rapid and effective then the infrared drying method. In the next study, the effect on the quality parameters of the products dried by these two drying methods will be investigated.

\section{References}

1. Kostermans, A.J.H.G., Bompard, J.M. The Mangoes: Their Botany, Nomenclature, Horticulture and Utilization. Academic Press, London, 1993.

2. FAO (United Nations Food and Agriculture Organization), Statistics Division (2013) Production/Crops of Mangoes Including Mangosteens and Guavas for 2013. Retrieved 13 April 2016.

3. USDA (National Nutrient Database for Standard Reference), https://ndb.nal.usda.gov/ndb/foods/show $/ 2271$ ?fgcd $=$ \&manu $=\& l f a c e t=\&$ format $=$ \&count $=\&$ max $=35 \&$ offset $=\&$ sort $=\& q$ lookup=mango" Retrieved 13 April 2016.

4. Akoy, E.O.M. Experimental Characterization and Modeling of ThinLayer Drying of Mango Slices. International Food Research Journal, 2014; 21, 1911-1917.

5. Pan, Z.; Khir, R.; Godfrey, L.D.; Lewis, R.; Thompson, J.R.; Salim, A. Feasibility of Simultaneous Rough Rice Drying and Disinfestations by Infrared Radiation Heating and Rice Milling Quality. Journal of Food Engineering, 2008; 84, 469-479.

6. Doymaz, I.; Kipcak, A.S.; Piskin, S. Characteristics of Thin-layer Infrared Drying of Green Bean. Czech Journal of Food Science, 2015a; 33, 83-90.

7. Lin, T.M.; Durance, T.D.; Scaman, C.H. Characterization of Vacuum Microwave Air and Freeze Dried Carrot Slices. Food Research International, 1998; 4, 111-117.

8. Sharma, G.P.; Prasad, S. Optimization of Process Parameters for Microwave Drying of Garlic Cloves. Journal of Food Engineering, 2006; 75, 441-446. 
9. Zielinska, M.; Zapotoczny, P.; Alves-Filho, O.; Eikevik, T.M.; Blaszczak, W. A Multi-Stage Combined Heat Pump and Microwave Vacuum Drying of Green Peas. Journal of Food Engineering, 2013; 115, 347-356.

10. Giri, S.K.; Prasad, S. Drying Kinetics and Rehydration Characteristics of Microwave-Vacuum and Convective Hot-Air Dried Mushrooms. Journal of Food Engineering, 1998; 78, 512-521.

11. Bondaruk, J.; Markowski, M.; Błaszczak, W. Effect of Drying Conditions on the Quality of Vacuum-microwave Dried Potato Cubes. Journal of Food Engineering, 2007; 81, 306-312.

12. Bilbao-Sáinz, C.; Andrés, A.; Chiralt, A.; Fito, P. Microwaves Phenomena during Drying of Apple Cylinders. Journal of Food Engineering, 2006; 74, 160-167.

13. Feng, H.; Tang, J.; Mattinson, D.S.; Fellman, J.K. Microwave and Spouted Bed Drying of Frozen Blueberries: The Effect of Drying and Pretreatment Methods on Physical Properties and Retention of Flavor Volatiles. Journal of Food Process Preservation, 1999; 23, 463-479.

14. Yongsawatdigul, J.; Gunasekaran, S.F. Microwave-vacuum Drying of Cranberries: Part II. Quality Evaluation. Journal of Food Process Preservation, 1996; 20, 145-156.

15. Abano, E.E. Kinetics and Quality of Microwave-Assisted Drying of Mango (Mangifera indica). International Journal of Food Science, 2016; Article ID 2037029, http://dx.doi.org/10.1155/2016/2037029.

16. Chayjan, R.A.; Kaveh, M. Drying Characteristics of Eggplant (Solanum melongena L.) Slices under Microwave-convective Drying. Research Agricultural Engineering, 2016; 62, 170-178.

17. Kipcak, A.S. Microwave Drying Kinetics of Mussels (Mytilus edulis). Research Chemistry Intermediation., 2016; DOI: 10.1007/s11164-016-2707-4.

18. Nowak, D.; Lewicki, P.P. Infrared Drying of Apple Slices. Innovative Food Science Emergency and Technology, 2004; 5, 353-360.

19. Adak, N.; Heybeli, N.; Ertekin, C. Infrared Drying of Strawberry. Food Chemistry, 2017; 219, 109-116.

20. Ruhanian, S.; Movagharnejad, K. Mathematical Modeling and Experiemntal Analysis of Potato Thin-Layer Drying in An InfraredConvective Dryer. Engineering Agricultural and Environmental Food 2016; 9, 84-91.

21. Doymaz, I. Drying of Potato Slices: Effect of Pre-treatments and Mathematical Modeling. Journal of Food Process Preservation, 2012; 36, 310-319.
22. Nasiroglu, S.; Kocabiyik, H. Thin-Layer Infrared Radiation Drying of Red Pepper Slices. Journal of Food Process Engineering, 2009; 32, 116.

23. Diamante, L.M.; Ihns, R.; Savage, G.P.; Vanhanen, L. A New Mathematical Model for Thin Layer Drying Fruits. International Journal of Food Science and Technology, 2011; 45, 1956-1962.

24. Dissa, A.O.; Desmorieux, H.; Bathiebo, J.; Koulidiati, J. Convective Drying Characteristics of Amelie Mango (Mangifera indica L. cv. 'Amelie') with Correction for Shrinkage. Journal of Food Engineering, 2008; 88, 429-437.

25. AOAC. Official Method of Analysis. Association of Official Analytical Chemists , Arlington, 1990.

26. Aghbashlo, M.; Kianmehr, M.H.; Khani, S.; Ghasemi , M. Mathematical Modeling of Carrot Thin-layer Drying Using New Model. International Agrophysics, 2009; 23, 313-317.

27. Chinenye, N.M.; Ogunlowo, A.S.; Olukunle, O.J. Cocoa Bean (Theobroma cacao L.) Drying Kinetics. Chilean Journal of Agricultural Research, 2010, 70, 633-639.

28. Midilli, A.; Kucuk, H. Mathematical Modeling of Thin Layer Drying of Pistachio by Using Solar Energy. Energy Convention Management, 2003; 44, 1111-1122.

29. Tunde-Akintunde, T.Y.; Ogunlakin G.O. Mathematical Modeling of Drying of Pretreated and Untreated Pumpkin. Journal of Food Science and Technology, 2013; 50, 705-713.

30. Sharma, G.P.; Verma, R.C.; Pathare, P.B. Thin-Layer Infrared Radiation Drying of Onion Slices. Journal of Food Engineering, 2005; 67, 361-366.

31. Sarimeseli, A.; Yuceer, M. Investigation of Infrared Drying Behaviour of Spinach Leaves Using ANN Methodology and Dried Product Quality. Chemistry Process Engineering, 2008; 36, 425-436.

32. Arslan, D.; Ozcan, M.M. Study the Effect of Sun, Oven and Microwave Drying on Quality of Onion Slices. LWT-Food Science Technology, 2010; 43, 1121-1127, 2010.

33. Motevali, A.; Minaei, S.; Khoshtaghaza, M.H.; Kazemi, M.; Nikbakht, A.M. Drying of Pomegranate Arils: Comparison of Predictions from Mathematical Models and Neural Networks. International Journal of Food Engineering, 2010; 6(3), Article 15.

34. Zogzas, N.P.; Maroulis, Z.B.; Marinos-Kouris, D. Moisture Diffusivity Data Compilation in Foodstuffs. Drying Technology, 1996; 14, 2225-2253. 